\title{
МИРОВОЙ ПОРЯДОК
}

\author{
Р. Н. Майоров
}

\section{ПОЛИТИЧЕСКАЯ ТЕОРИЯ В США КАК ПРОСТРАНСТВО ФОРМИРОВАНИЯ НАЦИОНАЛЬНОЙ ИДЕОЛОГИИ}

\begin{abstract}
Аннотация. $B$ статье рассматриваются особенности и внутренние противоречия политической теории США, ее способность на современном этапе формировать национальную идеологию и подпитывать национальную идею американского народа. Политическая теория в Соединенных Штатах Америки изначально развивалась как особый раздел американской политической науки, призванный обосновать эффективность как американской политологии, так и американской политической системы. В статье выявлены и сформулированы системные ограничения, налагаемые подражанием американской политической теории естественнонаучным дисииплинам и следованием идее «американской исключительности». Методологической базой исследования является системный, структурно-функииональный, сравнительно-исторический и сравнительно-политический подходы, методы анализа, синтеза, наблюдения, моделирования. Провозглашая свободу от иенностей в исследовании, политическая теория США на деле крайне тесно связана с иенностями либерализма. Этот своеобразный догматизм в сочетании с неприятием критики делает американскую политическую теорию схожей с коммунистическим учением, уподобляет ее идеологии. В пользу этого говорит и тот факт, что Американская ассоииаџия политической науки не слишком поочряет инакомыслие в своих рядах, как свидетельствуют сами американские политологи. В конечном счете накопленные в сфере политической теории противоречия препятствуют подлинно объективному исследованию политики и развитию политологии в США.
\end{abstract}

Ключевые слова: политика, общество, США, политическая теория, идеология, дипломатия, государство, история политики, ценности, безопасность.

Abstract. This article explores the peculiarities and internal contradictions of the U. S. political theory, as well as its ability to form national ideology and feed the national idea of American people at the present stage. The U. S. political theory was initially developing as a special chapter of the American political science, called to establish both, the effectiveness of American political science, as well as the American political system. The author determines and formulates the systemic limitations imposed by the imitation of the American political theory by the natural science disciplines and following the idea of "American exclusivity". Declaring the freedom from values in the research, the U. S. political theory is in fact closely tied to the values of liberalism. This unique dogmatism in combination with rejection of criticism makes the American political theory similar to the Communist teachings, and resembles its ideology. It is also justified by the fact that the American Political Science Association does not really tolerate dissent in its ranks, as substantiated by the actual American political scientists. In the end, the contradictions accumulated in the area of political theory impede the truly objective political research and development of political science in the United States.

Keywords: Security, Values, Political history, State, Diplomacy, Ideology, Political theory, United States, Society, Policy.

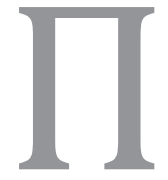

олитическая теория в США выступала полем обсуждения путей развития политической науки, и потому эта субдисциплина была пространством постоянных конфликтов между разными течениями и группами в американской политологии. Другой фактор, обусловивший конфликтный характер политической теории в США, имел внешний по отношению к политологии и сообществу поли- тологов характер. Этим фактором выступала сама политика, политическая борьба в США и мире. Политическая теория в США выступала как пространство конкуренции политических идеологий.

Ключевым аргументом критики американской политической теории, в том числе самокритики, исходившей от различных американских политологов, является внутренний конфликт 


\section{Тренды и управление 2(14) • 2016}

в американской политологии, обусловленный противоречием между двумя ключевыми целями американской политологии: с одной стороны, стремлением к построению объективной и строгой политической науки по образцу естественнонаучных дисциплин, с другой стороны - стремлением к обоснованию значимости и непогрешимости американского политического строя. Как отмечает один из исследователей, «американская политология исторически стремилась к исполнению двух функций, которые зачастую взаимосвязаны друг с другом: легитимировать и совершенствовать проект либеральной капиталистической демократии и стать более «научной» [1].

Прежде чем анализировать причины и следствия этого противоречия, следует обосновать наличие двух указанных трендов, охарактеризовать специфику их развития.

Идея построения политической науки по образцу естественнонаучных дисциплин была обусловлена всей историей развития политологии в США. В конце XIX - начале XX вв. интенсивный рост числа учебных заведений и студентов в США способствовал обособлению все новых и новых дисциплин, росту их специализации. Став академической дисциплиной к концу XIX в. и учредив профессиональную ассоциацию (Американскую ассоциацию политической науки, далее ААПН) в 1903 г., американская политология обрела атрибуты самостоятельной науки, и потому стремилась утвердиться в этом качестве, приняв на вооружение передовую методологию, в качестве которой рассматривались математические методы, уже получившие распространение в социологии. Далее ориентация на «подлинную научность», сциентизм, нашла свое выражение в «Чикагской школе» Мерриама (20-е - 30-е гг. XX в.) и «бихевиоральной революции» (50-е - 60-е гг. XX в.). «Постбихевиорализм», провозглашенный Д. Истоном в 1969 [2], казалось, должен был ознаменовать конец эпохи сциентизма в американской политологии. Однако этого не произошло, свидетельством чему - продолжение деятельности основанного в 1967 г. Движения за новую политическую науку (Caucus for New Political Science) и появление Движения «Перестройка» (Perestroika Movement) в 2000 г.
Возникшие с разницей в 33 года движения выдвигали схожие требования [3], сводившиеся к необходимости изучения актуальных проблем адекватными методами, что означало отказ от примата количественных методов.

Таким образом, сциентизм остается характерной чертой американской политической науки и в наше время.

Идея превосходства, исключительности США и американской системы правления также присуща дисциплине на протяжении всей ее истории.

Изначально одним из приоритетов американской политической науки являлась подготовка граждан, разбирающихся в системе правления своей страны, разделяющих ценности, лежащие в ее основе. Эта функция «гражданского образования» («citizenship education») была тесно связана со стремлением американской политической науки быть ориентированной на практику, представлять знания и услуги для американского государства.

«Республиканская политическая наука и либеральная политическая экономия были тесно связаны с национальной идеологией американской исключительности ...», отмечает Д. Росс в своей работе «Происхождение американской социальной науки» [4].

Возможности для экспансивного развития на свободных территориях, особое географическое положение и вера в особую роль нового государства определяли веру в особый, отличный от европейского путь развития и стремление скорее создать собственную науку, чем следовать европейской традиции. Идея американской исключительности получила развитие не только в культуре новой нации, но и в науке, в том числе в политических исследованиях. В ключе обозначенной склонности к идеализации своей политической системы видится характерной оценка одного из популярных пособий конца 19 в.: «Вступление выражало предельное удовлетворение американской политической системой и содержанием самой книги» [5].

Несмотря на то, что именно в период становления американская политическая наука опиралась почти исключительно на опыт европейской традиции изучения политики, уже в это время убеждение в особом статусе Америки и в 
необходимости построения особой, новой науки стало одной из основных идей американских интеллектуалов. Как отмечает Д. Росс, «каждое поколение американских социальных ученых принимало апологетическое задание, завещанное им идеей американской исключительности, и лишь отчасти разрешало связанные с ней противоречия» [6].

Главным следствием идеи американской исключительности мы видим ориентацию социальных наук и политической науки в частности на практику, а именно на функционирование государственных институтов США. Идея о неприменимости европейских подходов для анализа американских реалий с одной стороны и насущная потребность в решении реальных задач государственного строительства с другой определили ориентацию американской политической науки на изучение политической системы США и условий ее формирования и развития. При этом ученые видели себя не только исследователями, но и участниками созидательного процесса по строительству новой нации и нового государства.

Этот настрой отражается, к примеру, в инаугурационной речи Президента Университета Миннесоты в 1869г.: «Государство нуждается не только в образованных избирателях; оно более и более требует, с ходом времени и расширением сферы интересов, экспертов в праве, управлении, в военной обороне. Я думаю, вскоре станет очевидным, что эта потребность столь сильна, что государство будет вынуждено предоставить средства и места для обучения этим знаниям в рамках таких наук, как политическая экономия, международное право, государственное управление ...» [7].

Главным и драматическим следствием столкновения этих двух особенностей американской политологии - сциентизма с одной стороны и веры в американскую исключительность с другой - стало то, что они противоречили таким установкам науки, как объективность и поиск истины. Говоря об объективности, мы имеем в виду, что сциентистский характер американской политологии требовал морального релятивизма, однако это порождало существенные противоречия. Во-первых, моральный релятивизм служил основанием для едкой критики бихевиоралис- тов со стороны их коллег, приверженных более традиционным методам анализа. Во-вторых, сами бихевиоралисты не были чужды ценностей. Сохраняя миф об американской исключительности, они не могли не защищать американскую систему ценностей - то есть ценностей либеральной демократии. Маккартизм (конец 40-х - конец 50х гг. XX в.), общественное движение, направленное на борьбу с инакомыслием и поиск внутренних врагов в американском обществе, был своего рода проекцией этого стремления оградить идею американской исключительности от посягательств. С другой стороны, говоря о поиске истины, мы должны указать, что идея американской исключительности, так же как и сциентизм, накладывали ограничения на поиск истины, комплексное и полное рассмотрение проблем в американской политологии. В одной из знаковых работ Карла Поппера «Открытое общество и его враги», сформулирована мысль, перенятая американской политической мыслью - только плюрализм идей может служить общему благу.

Однако, по иронии судьбы, именно плюрализма недостает американской политологии, свидетельство чему - уже упомянутые Движение за новую политическую науку и Движение «Перестройка». Некоторые исследования прямо указывают на связь руководства ААПН с ЦРУ [8], и в то время как вовлеченность в реальную политику (к примеру, протест против войны во Вьетнаме) называлась руководством ассоциации признаком непрофессионализма, сама ассоциация была тесно связана с правящими слоями государства.

Косность методологии стала своего рода нормой для американских исследователей и выражалась во всемерной поддержке со стороны ААПН количественных методов и теории игр при фактическом игнорировании целого ряда проблем, включая расовые, гендерные, и региональные как не отвечающих доминирующей ориентации на изучение американской политической системы как эталонной.

Любопытно, что единомыслие в рядах исследователей и защитников американской демократии поддерживалось не только на методологическом, но и на административном уровне. Так, одной из причин появления Движения за новую 


\section{Тренды и управление 2(14) • 2016}

политическую науку в 1967 г. стала непрозрачная система выдвижения и избрания руководства ААПН. Лишь два года спустя после учреждения Движения за новую политическую науку, в 1969, «впервые в истории ААПН был брошен вызов кандидатурам официального Комитета по выдвижению (official Nominating Committee), который исторически выдвигал лишь одну кандидатуру на каждый из постов ААПН» [8]. Тем не менее, эта борьба не увенчалась успехом, и в манифесте движения «Перестройка» 2000 г. мы находим схожие упреки в том, что «"избранный круг" доминирует и контролирует руководство AАПН и редакционный совет журнала American Political Science Review» [9]. Как видно, атмосфера ААПН с безальтернативными выборами и игнорированием альтернативных позиций отвечала скорее советским, чем подлинно демократическим реалиям.

На наш взгляд, причиной такой косности является гиперпрофессионализация политологии и вообще гуманитарных дисциплин в Америке. Как отмечает Л. Андерсон, «Судя по тому, как осуществляется подготовка большинства американских докторантов сегодня, дисциплины похожи на банды, с рукопожатиями и \{особыми\} цветами, с церемониями инициации и секретными паролями... Их члены ревностно оберегают территорию и легко переходят к высмеиванию, встречаясь с работами своих конкурентов» [10]. Субдисциплины политологии становятся замкнутыми цехами, осознающими свою связь с прошлыми поколениями. При этом свою историческую миссию политологи тесно связывают с развитием американского государства изащитой американской системы государственного устройства как единственно верного. Это и мешает им более открыто смотреть на вещи.

На наш взгляд, ограниченность американской политологии вследствие указанных причин - приверженности идее американской исключительности, сциентизма и своеобразного цехового самосознания - сделали американских политологов прослойкой столь же обособленной и уникальной, как русская революционная интеллигенция, а политическую науку в США - столь же косной, односторонней и уязвимой, как официальная советская идеология и научный коммунизм.
Таким образом, мы надеемся показать, что апологетика американской формы либеральной демократии превратила американскую политическую теорию в пространство догм, чуждое плюрализма.

Для начала остановимся на характеристиках русской революционной интеллигенции. Классическое определение русской интеллигенции связано с именем философа Н.А. Бердяева, который в своей работе «Истоки и смысл русского коммунизма» выделяет ряд характерных для нее черт - отторжение Запада (Европы) как неудавшегося проекта построения справедливого общества; мессианство, убежденность в необходимости служения великому делу; противопоставление себя государству; устремленность в будущее или прошлое, «раскол с современностью».

Пристальный анализ особенностей развития американской политологии позволяет обнаружить перечисленные признаки у американских политологов.

Безусловно, Европа для политологов США также представала как неудачный проект развития человеческого общества - в противовес Америке, призванной на новой почве построить общество подлинно процветающее и благополучное. Это благополучие виделось возможным за счет огромного потенциала свободных пространств Америки, которые служили залогом того, что в США, в отличие от Европы, незачем бояться массовой бедности и предостережений мальтузианцев. Идея пространственного отличия от Европы означает и упомянутую устремленность в будущее - безусловно, американские интеллектуалы были ориентированы на решение насущных проблем нового государства, но вместе с тем именно вера в его перспективы объясняла их энтузиазм.

Уже упомянутая идея американской исключительности закономерно ведет и к особого рода мессианству, представлениям о глобальной миссии Америки в мире. «Идея американской исключительности, таким образом, была набором взаимосвязанных идей, - к примеру, можно вычленить вопрос о миссии Америки в мире, - рамки которого было трудно определить. В целом, идея американской исключительности была националистической (nationalist) идеологией...» [11], отмечает Д. Росс. 
Мы легко можем найти свидетельства восприятия американскими политологами своей профессии как особой, имеющей исключительное значение для США и всего мира. В их сочинениях гордость за страну и гордость за профессию идут рука об руку. К примеру, С. Хантингтон писал: «Нет американской политической науки; есть демократическая политическая наука, которая впервые и наиболее полно развилась в Соединенных Штатах, потому что Соединенные штаты были первой и наиболее полной демократией в современном мире» [12]. Г. Алмонд в 1988 г. писал: «Мы обладаем хорошими основаниями для профессиональной гордости за развитие политической науки в последние десятилетия. И как американцы мы внесли важный вклад в развитие в более чем столетнего и всемирного стремления применить силу знания для решения трагических дилемм мира политики» [13].

В заключение нашего анализа следует сказать, что американские политологи не противопоставляли себя государству - напротив, отождествляли себя с ним, его нуждами и успехами. Но, с момента получения независимости, они жили в государстве, уже совершившем своего рода революцию, освободившись от владычества Великобритании.

Таким образом, американские политологи предстают перед нами как своего рода аналог российской дореволюционной интеллигенции - убежденные в своей правоте, в необходимости служения нации, в возможности построения, не имеющего аналогов в мировой истории государства.

Возвращаясь к американской политической науке, мы можем отметить ее сходство с догматами марксистского учения и советской идеологией. Американская политическая наука стремилась с помощью как можно более «научной» аргументации (под которой понимались математические методы) доказать постулат, истинность которого не подвергалась сомнению. Этим постулатом была идея американской исключительности. Изначально исключительность эта связывалась скорее с особым пространственным положением Нового Света, однако со временем укоренилось убеждение и в особой роли американских политических институтов.
У Бернштейна мы находим аналогичное описание марксистского учения: всячески подчеркивая свою научность, марксизм как разновидность социализма стремился обосновать постулат о неизбежности установления социалистического строя - постулат, истинность которого на подвергалась сомнению. «... никакой “изм” не может быть наукой. “Измом” мы обозначаем миросозерцание, тенденцию, систему мыслей или требование, но не науку» [14]. Иными словами, призвание науки - поиск истины, а не поиск подтверждений принимаемого на веру постулата.

Подобно тому, как социализм был чем-то большим, чем научное предприятие-движением, идеологией, учением, и потому обладал идеалистическим компонентом - американская политология и политическая теория не есть лишь наука, но также своего рода движение и способ обоснования и воплощения идеи американской исключительности.

Предложенная нами параллель между американскими политологами и русской интеллигенцией, между американской политологией и научным коммунизмом подтверждается названием движения «Перестройка», Perestroika Movement, возникшего в американской политической науке в 2000 г. Заимствование этого советского термина указывало на необходимость борьбы с косностью, необъективностью американской политической науки. Для описания ситуации были использованы и иные термины, например, характер формирования органов управления ААПН был назван «номенклатурным» [15].

Несмотря на то, что идея американской исключительности разделяется большинством американских идеологов, существуют определенные отличия в ее трактовке. Наряду с методологией, идеология в США является основанием для разделения политической теории на ряд противоборствующих лагерей.

К примеру, следует отметить «правых», последователей Лео Штрауса, (называемых также Штрауссианцами и «неоконами», некоторые из которых заняли заметные позиции в администрации президента Дж. Буша - младшего). И сама фигура Штрауса, и его учение обросли целым рядом противоречащих друг другу интерпретаций: Штрауса называют и идеологом «платонического либерализма», и консерватором, и 


\section{Тренды и управление 2(14) • 2016}

другом демократии, и ее врагом [16-21]. С точки зрения идеологии в позиции Штрауса следует отметить в первую очередь отказ от морального релятивизма, который в свою очередь требует более активной внешней политики (в противовес идее невмешательства). Вторая черта, имеющая значение преимущественно для внутренней политики, заключается в эзотеризме, стремлении к прочтению скрытого смысла политических учений и текстов, что в свою очередь подразумевает элитарность политического знания, дистанцию между правителями и советниками с одной стороны и менее образованным большинством - с другой.

Примером более мягкой альтернативы выступают теоретики, стремящиеся включить в политическую и исследовательскую повестку новые проблемы американского общества - такие, как вопросы сексуальных меньшинств, феминизма, антимилитаризма, расового неравенства, и др.
На другом конце спектра находятся «левые», влияние которых сравнительно невелико и которые в целом скорее не разделяют идею американской исключительности как «империалистическую».

Тем не менее, мы должны заключить следующее. Политическая теория в США выступает, в том числе, как пространство идеологии. Развитие политической теории в США определяется не только логикой институционализации политической науки и изменения учебных программ подготовки политологов, но и стремлением сформировать национальную идеологию, в центре которой - идея американской исключительности, превосходства американской системы правления. Политическая теория в США - это результат работы американских политологов как особой прослойки интеллектуалов, склонной к идеализации собственного государства и осознания своей миссии как служения этому государству.

\section{Библиография}

1. Warren D.T., Will the real perestroikniks please stand up? // Perestroika! The raucous rebellion in political science Edited by Kristen Renwick Monroe, Yale University Press, 2005, p. 219;

2. Easton, D. The New Revolution In Political Science // American Political Science Review, December 1969;

3. Sailsbury, R., Current Criticism of APSA is Nothing New // PS: Political Science and Politics, 34 (December 2001) 767-772;

4. Ross D. The origins of American Social Science, Cambridge, 1991, p.48;

5. Haddow A. Political science in American colleges and universities 1636-1900, Octagon Books, N.Y., 1969, p. 236;

6. D. Ross, The origins of American Social Science, Cambridge, 1991, p.76;

7. Haddow A. Political science in American colleges and universities 1636-1900, Octagon Books, N.Y., 1969, p. 212;

8. Barrow, C.W. The Intellectual Origins of New Political Science // New political science, Vol. 30, Issue 2, 2008.

9. The Idea // Perestroika! The raucous rebellion in political science Edited by Kristen Renwick Monroe, Yale University Press, 2005, p. 9;

10. Anderson L., Items and Issues, Social Science Research Council, Vol. I, №III-IV, Fall 2000, p. 8

11. Ross D. The origins of American Social Science, Cambridge, 1991, p. 28;

12. Huntington S.P., One Soup at a Time: Political Science and Political Reform // American Political Science Review, vol. 82, №2, March 1988 pp. 6-7;

13. Almond G. Separate Tables: Schools and Sects in Political Science // PS: Political Science and Politics, Vol. 21, No. 4 (Autumn, 1988), p. 840;

14. Бернштейн Э. Издательство Буревестник, Одесса, 1906 г. Стр. 27-28 
15. Posusney, M.P. Democracy versus Diversity - a False Dichotomy // Perestroika! The raucous rebellion in political science Edited by Kristen Renwick Monroe, Yale University Press, 2005, p. 250-259;

16. Chacon, R. Reading Strauss from the Start: On the Heideggerian Origins of 'Political Philosophy' // European Journal of Political Theory 2010 Vol. 9, 287-307

17. Altman, W.H.F., The Hindenburg Line of the Strauss Wars // Philosophy of the Social Sciences March 2010 Vol. 40, №1, pp. 118-153;

18. Barber, B.R. The Politics of Political Science: "Value-free" Theory and the Wolin-Strauss Dust-Up of 1963 // American Political Science Review, November 2006, Vol. 100, No. 4, 539-545;

19. Frisch, M.J., Leo Strauss and the American Regime // Publius, Vol. 17, No. 2 (Spring, 1987), pp. 1-5; Smith S.B., Leo Strauss's Platonic Liberalism // Political Theory Vol. 28, No. 6 (Dec., 2000), pp. 787-809;

20. Павлов А.В., Прагматичные наследники политической философии Лео Штрауса // История философии. 2008. №13. С. 98-109;

21. Павлов А.В., Лео Штраус: искусство писать и искусство читать // Социологическое обозрение. 2012. Т. 3. №3. С. 4-11.

22. Бочарников И.В. О государственной идеологии России // Международные отношения.-2013.-1.-С. 22-27. DOI: 10.7256/2305-560Х.2013.01.3.

23. Манойло А.В. Сирийский тупик «Арабской весны». // Вестн. Моск. Ун-та. Сер. 12. Политические науки. 2013. №6. С. 49-56.

24. Манойло А.В. Политические конфликты в международных отношениях и мировой политике. //Мир и Политика. 2013. №2. С. 71-82.

25. Карпович О.Г. Идеологическая база сепаратизма в системе координат современной мировой политики // Политика и Общество. - 2014. - 11. - C. 1339 - 1352. DOI: 10.7256/1812-8696.2014.11.12959.

26. Карякин В.В. Цивилизационная антропология американского экспансионизма: от доктрины Монро к глобальному лидерству // Международные отношения. - 2013. - 4. - C. 487 - 468. DOI: 10.7256/2305-560Х.2013.4.9722.

27. Ласария А.О. Особенности этнополитических конфликтов на постсоветском пространстве // Международные отношения. - 2015. - 1. - С. 75 - 77. DOI: 10.7256/2305-560X.2015.1.13507.

28. Фельдман П.Я. Геополитический клиентелизм в международных отношениях: стратегия и тактика Запада. // Международные отношения. - 2014. - 2. - C. 189 - 193. DOI: 10.7256/2305-560Х.2014.2.11365.

29. Спиридонов В.В. Финансово-экономические причины политического кризиса на Украине. Взгляд через призму анализа банковской системы страны // Международные отношения. - 2014. - 3. - С. 398 - 405. DOI: 10.7256/2305-560X.2014.3.11740.

\section{References (transliterated)}

1. Warren D.T., Will the real perestroikniks please stand up? // Perestroika! The raucous rebellion in political science Edited by Kristen Renwick Monroe, Yale University Press, 2005, p. 219;

2. Easton, D. The New Revolution In Political Science // American Political Science Review, December 1969;

3. Sailsbury, R., Current Criticism of APSA is Nothing New // PS: Political Science and Politics, 34 (December 2001) 767-772;

4. Ross D. The origins of American Social Science, Cambridge, 1991, p.48;

5. Haddow A. Political science in American colleges and universities 1636-1900, Octagon Books, N.Y., 1969, p. 236;

6. D. Ross, The origins of American Social Science, Cambridge, 1991, p.76;

7. Haddow A. Political science in American colleges and universities 1636-1900, Octagon Books, N.Y., 1969, p. 212; 


\section{Тренды и управление 2(14) • 2016}

8. Barrow, C.W. The Intellectual Origins of New Political Science // New political science, Vol. 30, Issue 2, 2008.

9. The Idea // Perestroika! The raucous rebellion in political science Edited by Kristen Renwick Monroe, Yale University Press, 2005, p. 9;

10. Anderson L., Items and Issues, Social Science Research Council, Vol. I, №III-IV, Fall 2000, p. 8

11. Ross D. The origins of American Social Science, Cambridge, 1991, p. 28;

12. Huntington S.P., One Soup at a Time: Political Science and Political Reform // American Political Science Review, vol. 82, №2, March 1988 pp. 6-7;

13. Almond G. Separate Tables: Schools and Sects in Political Science // PS: Political Science and Politics, Vol. 21, No. 4 (Autumn, 1988), p. 840;

14. Bernshtein E. Izdatel'stvo Burevestnik, Odessa, 1906 g. Str. 27-28

15. Posusney, M.P. Democracy versus Diversity - a False Dichotomy // Perestroika! The raucous rebellion in political science Edited by Kristen Renwick Monroe, Yale University Press, 2005, p. 250-259;

16. Chacon, R. Reading Strauss from the Start: On the Heideggerian Origins of 'Political Philosophy' // European Journal of Political Theory 2010 Vol. 9, 287-307

17. Altman, W.H.F., The Hindenburg Line of the Strauss Wars // Philosophy of the Social Sciences March 2010 Vol. 40, №1, pp. 118-153;

18. Barber, B.R. The Politics of Political Science: "Value-free" Theory and the Wolin-Strauss Dust-Up of 1963 // American Political Science Review, November 2006, Vol. 100, No. 4, 539-545;

19. Frisch, M.J., Leo Strauss and the American Regime // Publius, Vol. 17, No. 2 (Spring, 1987), pp. 1-5; Smith S.B., Leo Strauss's Platonic Liberalism // Political Theory Vol. 28, No. 6 (Dec., 2000), pp. 787-809;

20. Pavlov A.V., Pragmatichnye nasledniki politicheskoi filosofii Leo Shtrausa // Istoriya filosofii. 2008. №13. S. 98-109;

21. Pavlov A.V., Leo Shtraus: iskusstvo pisat' i iskusstvo chitat' // Sotsiologicheskoe obozrenie. 2012. T. 3. №3. S. 4-11.

22. Bocharnikov I.V. O gosudarstvennoi ideologii Rossii // Mezhdunarodnye otnosheniya.-2013.-1.-C. 22-27. DOI: 10.7256/2305-560X.2013.01.3.

23. Manoilo A.V. Siriiskii tupik «Arabskoi vesny». // Vestn. Mosk. Un-ta. Ser. 12. Politicheskie nauki. 2013. №6. S. 49-56.

24. Manoilo A.V. Politicheskie konflikty v mezhdunarodnykh otnosheniyakh i mirovoi politike. //Mir i Politika. 2013. №2. S. 71-82.

25. Karpovich O.G. Ideologicheskaya baza separatizma v sisteme koordinat sovremennoi mirovoi politiki // Politika i Obshchestvo. - 2014. - 11. - C. 1339 - 1352. DOI: 10.7256/1812-8696.2014.11.12959.

26. Karyakin V.V. Tsivilizatsionnaya antropologiya amerikanskogo ekspansionizma: ot doktriny Monro k global'nomu liderstvu // Mezhdunarodnye otnosheniya. - 2013. - 4. - C. 487 - 468. DOI: 10.7256/2305-560X.2013.4.9722.

27. Lasariya A.O. Osobennosti etnopoliticheskikh konfliktov na postsovetskom prostranstve // Mezhdunarodnye otnosheniya. - 2015. - 1. - C. 75 - 77. DOI: 10.7256/2305-560X.2015.1.13507.

28. Fel'dman P.Ya. Geopoliticheskii klientelizm v mezhdunarodnykh otnosheniyakh: strategiya i taktika Zapada. // Mezhdunarodnye otnosheniya. - 2014. - 2. - C. 189 - 193. DOI: 10.7256/2305-560X.2014.2.11365.

29. Spiridonov V.V. Finansovo-ekonomicheskie prichiny politicheskogo krizisa na Ukraine. Vzglyad cherez prizmu analiza bankovskoi sistemy strany // Mezhdunarodnye otnosheniya. - 2014. - 3. - C. 398 - 405. DOI: 10.7256/2305-560X.2014.3.11740. 